\title{
Cytogenetic and histological studies of testicular biopsies from subfertile men with chromosome anomaly
}

\author{
M J W FAED, * M A LAMONT, * AND K BAXBY $\dagger$ \\ From * the Cytogenetics Laboratory, University of Dundee, Ninewells Hospital and Medical School, and \\ $\dagger$ Department of Urology, Dundee Royal Infirmary, Dundee.
}

SUMmARY Testicular biopsies from eight men with abnormal karyotypes have been examined for histological and cytogenetic evidence of disturbances of meiosis. Quantitative analysis of this material showed one, with a 13;14 Robertsonian translocation, to have apparently normal spermatogenesis. Three patients, one with a 47,XYY and two with 46,XY, inv 9 karyotypes, had an overall depression of spermatogenesis. Four others, all with major chromosomal abnormalities, had apparently normal spermatogenesis until the primary spermatocyte stage. Two of these had sex autosomal translocations. One, 46,Y,t $(\mathrm{X} ; 21)$, had a complete block at $\mathrm{MI}$, the other, 46,X,t(Y;16), had a partial block at spermatid formation. One man with a reciprocal 2;10 translocation showed delay at all stages beyond spermatocyte formation and one man with an inversion of chromosome 3 showed impaired spermatid maturation.

The association between subfertility and chromosome anomaly has been noted in a number of surveys of male subfertility clinics. ${ }^{1-3}$ Although this may be the result of loss of zygotes with an unbalanced chromosome complement, it is evident that there may also be a direct effect on spermatogenesis. ${ }^{4}$ However, the role of chromosomal anomaly in spermatogenic failure is not clear, as testicular biopsies from subfertile men with chromosome abnormality are not often available.

In the course of a continuing study of the Received for publication 26 March 1981. karyotypes of all patients presenting at a male subfertility clinic, part of which has already been reported, ${ }^{3}$ we have obtained testicular biopsies for histological and cytogenetic studies from eight men with abnormal karyotypes, including two with sex chromosome/autosome translocations.

These observations and our attempts to relate the chromosomal and histological findings form the subject of this report.

\section{Material and methods}

All eight patients in this report had attended a male

TABLE 1 Karyotypes, ages, sperm counts, reproductive histories, and available family studies of 8 subfertile men

\begin{tabular}{|c|c|c|c|c|c|c|c|}
\hline Patient & Karyotype & Age & $\begin{array}{l}\text { Sperm count } \\
\left(\times 10^{6} / \mathrm{ml}\right)\end{array}$ & $\begin{array}{l}\text { No of years } \\
\text { of involuntary } \\
\text { subfertility }\end{array}$ & $\begin{array}{l}\text { Reported } \\
\text { abortions in } \\
\text { spouse }\end{array}$ & $\begin{array}{l}\text { Successful } \\
\text { pregnancy } \\
\text { within } 1 \\
\text { year of } \\
\text { attending clinic }\end{array}$ & Family studies \\
\hline $269 / 76$ & $46, Y, t(X ; 21)(q 23 ; q 11)$ & 30 & 0 & 4 & - & - & - \\
\hline $489 / 79$ & $46, X, t(Y ; 16)(q 11 ; q 13)$ & 36 & 1 & 7 & 2 & 一 & $\begin{array}{l}\text { Father } 46, X Y \\
\text { Brother } 46, X Y\end{array}$ \\
\hline $452 / 75$ & $47, X Y Y$ & 28 & 3 & 4 & 一 & - & Father $46, X Y$ \\
\hline $22 / 76$ & $45, X Y, t(13 q 14 q)$ & 25 & 20 & 2 & 一 & + & Daughter $46, \mathrm{XX}$ \\
\hline $136 / 76$ & $46, X Y, t(2 ; 10)(q 33 ; q 24)$ & 40 & 20 & 7 & - & + & $\begin{array}{l}\text { Father } 46, \mathrm{XY}, \mathrm{t}(2 ; 10) \\
\text { Mother } 46, \mathrm{XX} \\
\text { Sister } 46, \mathrm{XX}\end{array}$ \\
\hline $625 / 78$ & $46, X Y$,inv $3(\mathrm{p} 25 \mathrm{q} 21)$ & 33 & 8 & 10 & - & 一 & $\begin{array}{l}\text { Parents dead } \\
\text { Sister } 46, \mathrm{XX}\end{array}$ \\
\hline 695,78 & $46, X Y$, inv $9(p 12 q 12)$ & 39 & 2 & 6 & 1 & 一 & - \\
\hline $518 / 75$ & $46, X Y$, inv $9(\mathrm{p} 11 \mathrm{q} 12)$ & 29 & 1 & 2 & - & - & - \\
\hline
\end{tabular}


subfertility clinic and belonged to a group biopsied as part of their investigation. Before biopsy seven were known, from studies on lymphocytes, to have a chromosomal abnormality, but one translocation carrier was recognised only after meiotic studies had revealed the presence of a quadrivalent. Biopsies from ten subfertile patients with an apparently normal 46,XY karyotype are reported elsewhere. ${ }^{5}$

The karyotype, age, sperm count, reproductive history, and available family studies of each of the men are shown in table 1.

Biopsies were taken under general anaesthesia from both testes in two patients and from the right testis only in the others. Each specimen was immediately divided into two. One part, for histological examination, was fixed in Bouin's fluid, and the other placed in $1 \%$ sodium citrate for cytogenetic studies.
Cytogenetic preparations were made by the method of Evans et $a l^{6}$ or of Luciani et $a l^{7}$ for pachytene preparations. Counts were made of cells in spermatogonial metaphase, at diakinesis, and at metaphase II. A minimum of 50 dividing cells was counted from each biopsy. The average number of chiasmata per cell was obtained from at least ten well spread Giemsa stained cells, and all available cells at diakinesis, up to a maximum of 100 , were examined for abnormal chromosomal configurations and for dissociation of the sex chromosomes.

For assessment of the histological status of the biopsy, $7 \mu \mathrm{m}$ paraffin embedded sections were stained with haematoxylin and eosin. Details of the methods of assessment are given in our previous report of biopsies from 16 fertile and ten subfertile men with normal karyotype. ${ }^{5}$ Briefly, 100 tubules

TABLE 2 Cytogenetic analysis of testicular biopsies from 8 men with abnormal somatic karyotypes

\begin{tabular}{|c|c|c|c|c|c|c|}
\hline \multirow[b]{2}{*}{ Karyotype } & \multicolumn{3}{|c|}{ Cell distribution $(\%)$} & \multirow[b]{2}{*}{$\begin{array}{l}\text { Total cells } \\
\text { counted }\end{array}$} & \multirow{2}{*}{$\begin{array}{l}\text { Chiasma count } \\
\text { (average for } \\
10 \text { cells) }\end{array}$} & \multirow{2}{*}{$\begin{array}{l}\% \text { cells with } \\
X, Y \text { dissociation } \\
\text { at diakinesis }\end{array}$} \\
\hline & $\begin{array}{l}\text { Spermatogonial } \\
\text { division }\end{array}$ & Diakinesis & Metaphase II & & & \\
\hline $46, Y, t(X ; 21)$ & 0 & \multicolumn{2}{|c|}{ No cells seen beyond pachytene } & & - & 一 \\
\hline $46, X, t(Y ; 16)$ & 12 & 68 & 20 & 132 & $53 \cdot 1$ & 6 \\
\hline $47, X Y Y$ & 29 & 46 & 25 & 205 & 47.6 & 13 \\
\hline $45, X Y, t(13 ; 14)$ & 16 & 52 & 32 & 159 & $47 \cdot 6$ & 19 \\
\hline $46, X Y, t(2 ; 10)$ & 9 & 58 & 33 & 58 & $51 \cdot 0$ & 17 \\
\hline $46, X Y$,inv 3 & 6 & 56 & 38 & 75 & $46 \cdot 0$ & 10 \\
\hline $46, X Y$,inv 9 & 5 & 58 & 37 & 53 & $52 \cdot 4$ & 9 \\
\hline 46,XY,inv 9 & 8 & 57 & 35 & 83 & $53 \cdot 1$ & 16 \\
\hline Normal range (Lamont et $a l^{5}$ ) & 4-20 & $33-60$ & $31-55$ & $52-68$ & $42 \cdot 6-53 \cdot 6$ & $6-21$ \\
\hline
\end{tabular}

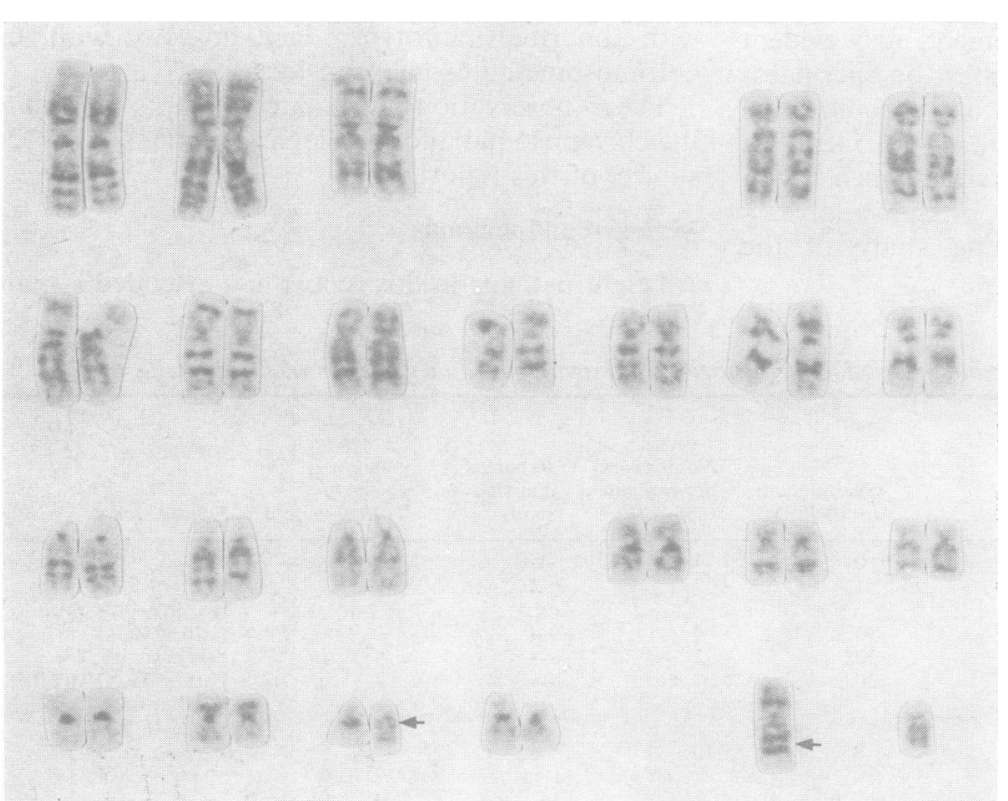

FIG 1 Mitotic karyotype of male with karyotype $46, Y, t(X ; 21) ;(q 23 ; q 11)$. 
from each biopsy were each scored on a scale for spermatogenesis from 1 (atrophic tubules) to 10 (complete spermatogenesis) ${ }^{8}$ and a mean biopsy score was calculated. The percentage volume of tubular epithelium was assessed by point counting ${ }^{9}$ and tangent counts were studied for any evidence of hypercurvature by the method of Averback and Wight. ${ }^{10}$

\section{Results}

\section{CYTOGENETIC STUDIES}

The cytogenetic findings for all eight men are shown in table 2 with the corresponding values for fertile men for comparison.

The distribution counts of dividing cells in all the patients were unremarkable and were within normal limits except in the two sex/autosome translocation carriers and the XYY patient. The $X ; 21$ translocation carrier had too few active cells to assess, the $Y ; 16$ translocation carrier had a high proportion of cells at diakinesis, and the XYY patient showed a relative increase in the number of cells in spermatogonial metaphase. Chiasma counts and the proportion of dissociated $\mathrm{X}$ and $\mathrm{Y}$ chromosomes were within normal limits in all the biopsies.

\section{Sex chromosome/autosome translocations}

The mitotic karyotype of the patient with the $\mathrm{X}$;autosome translocation is shown in fig 1 . In the meiotic preparations there were no cells seen in division and no cells were seen beyond pachytene. The sex vesicle usually appeared to be of irregular shape (fig 2).

A partial karyotype of the patient with the $Y ; 16$ translocation is shown in fig 3 . All cells at diakinesis

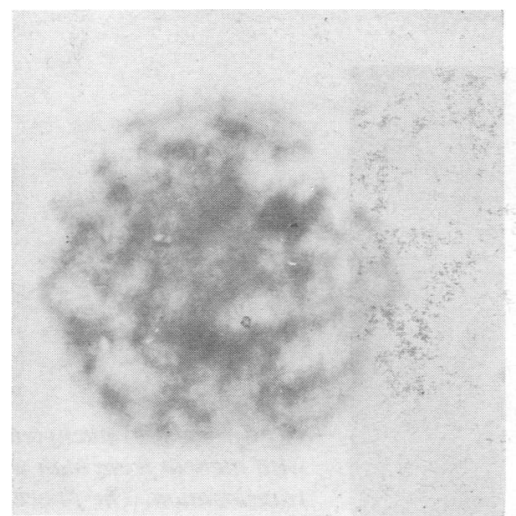

FIG 2 Pachytene cell with irregularly shaped sex vesicle from patient with $X ; 21$ translocation.

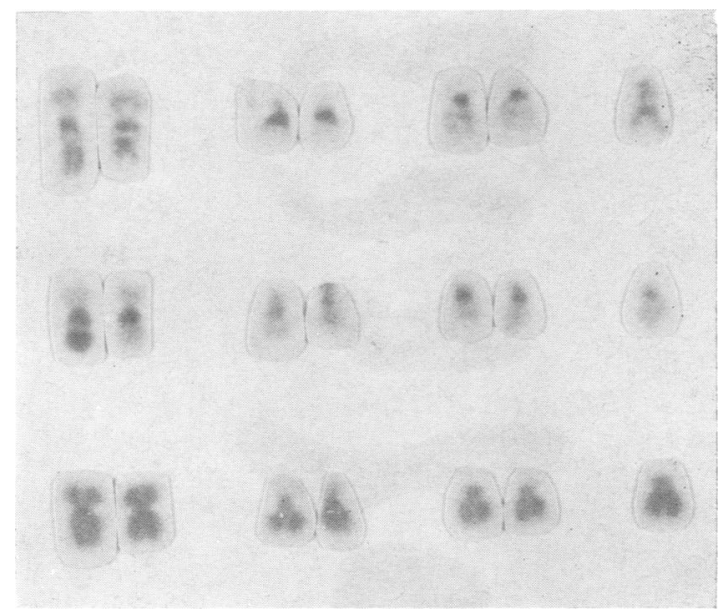

FIG 3 Partial mitotic karyotype from patient with karyotype 46,X,t $(Y ; 16)(q 11 ; q 13)$ with $G$ band, $C$ band, and orcein staining. Chromosomes 21 and 22 are included for size comparison.

(fig 4) revealed an extended chain made up, as shown in the diagram in fig 5 , of the $X$ chromosome, the $Y ; 16$ translocation chromosome, the normal 16, and the $16 ; Y$ translocation chromosome, of which the Yq portion on the end is clear both after atebrin staining and with $\mathrm{C}$ banding (fig 4). A total of 75 cells showed a simple chain formation, but in 14 cells

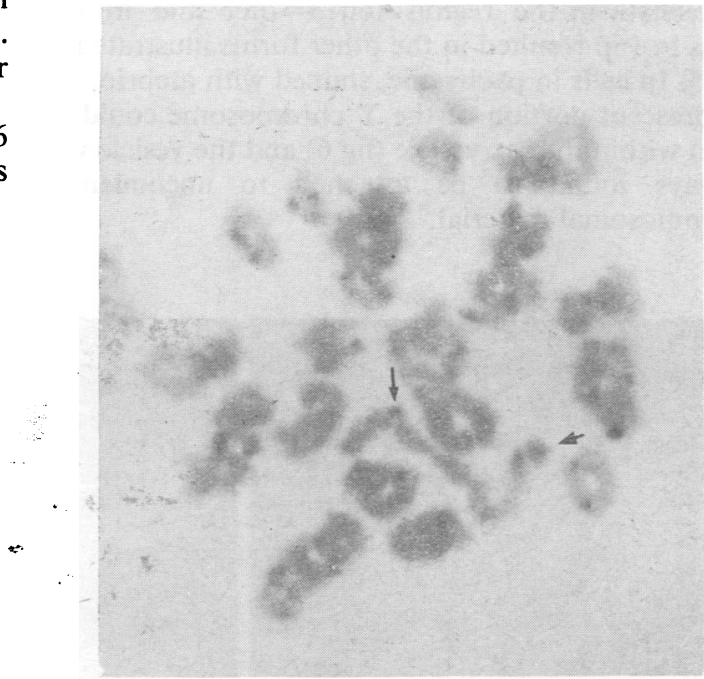

FIG 4 Cell in diakinesis from patient with $Y ; 16$ translocation, showing the extended chain seen in all cells. $C$ banded preparation. $\downarrow$ indicates the centromere of the $X$ chromosome. $\leftarrow$ indicates the $q$ portion of the $Y$ chromosome. 


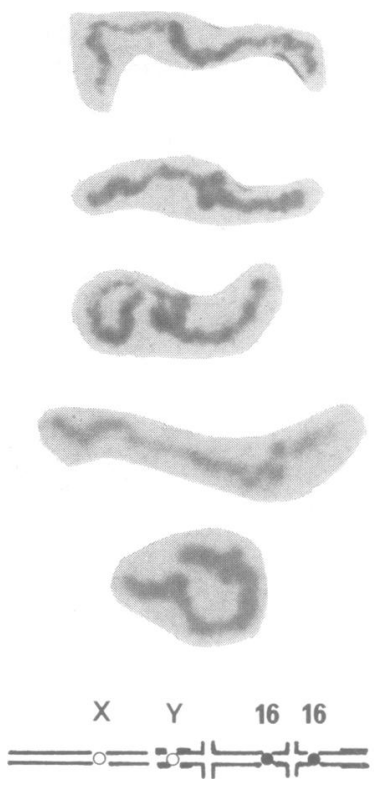

FIG 5 Extended chain configurations seen in diakineses from patient with $Y ; 16$ translocation. Giemsa stained.

Figures on right indicate number of cells with configuration illustrated. Position of centromeres is indicated in the diagram. Thick lines denote $Y$ chromosome material.

chiasmata in the region $16 \mathrm{q} 13 \rightarrow$ qter and in five cells in $16 \mathrm{p}$ resulted in the other forms illustrated in fig 5 . In cells in pachytene, stained with atebrin, the fluorescent portion of the Y chromosome could be seen within the sex vesicle (fig 6) and the vesicle was always found to be attached to uncondensed chromosomal material.

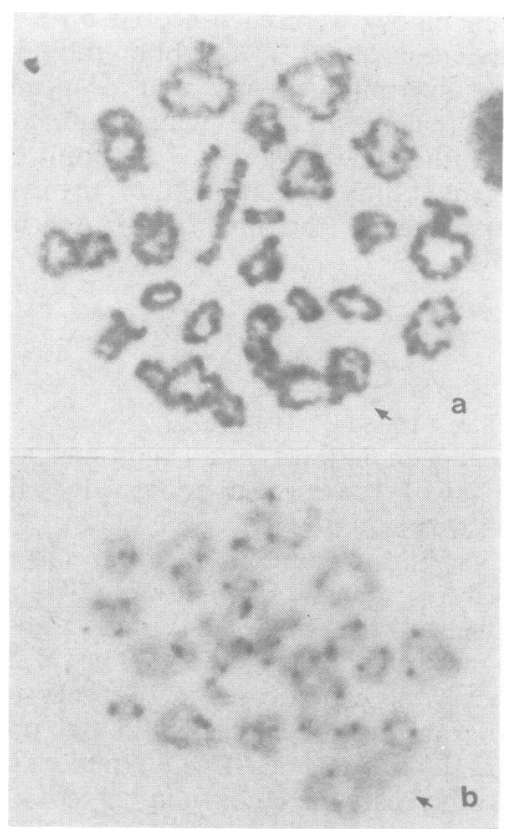

FIG 7 Diakineses from man with 2;10 translocation showing the large ring quadrivalent seen in all 34 cells examined. (a) Giemsa stained. (b) C banded preparation.

47, $X Y Y$

The cytogenetic findings for the $47, X Y Y$ patient have been fully reported elsewhere. ${ }^{11}$

\section{Autosome translocations}

All 66 cells analysed at diakinesis from the patient with a Robertsonian 13;14 translocation showed a trivalent; there was no evidence of failure of pairing.
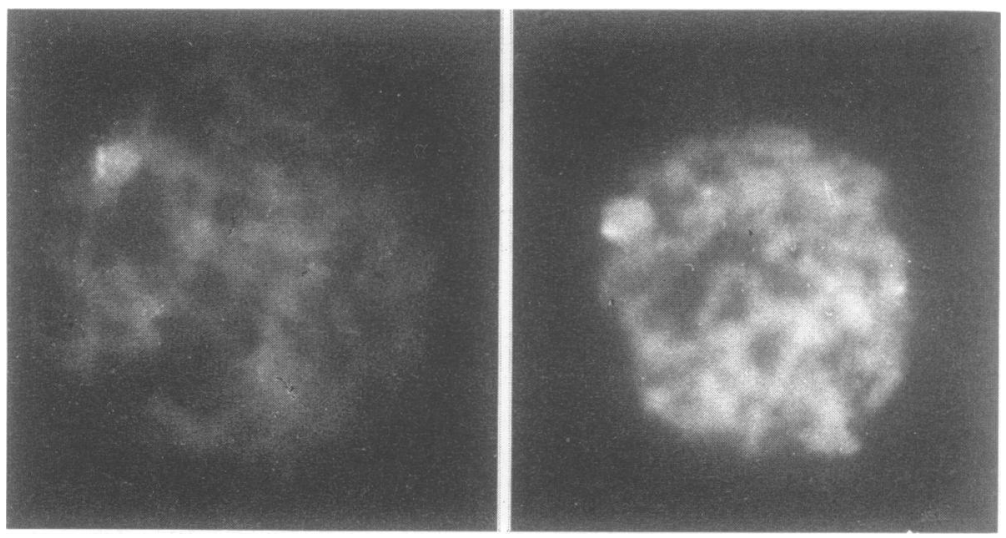

FIG 6 Cells at pachytene stained with atebrin from man with $Y ; 16$ translocation. The fluorescent portion of the $Y$ can be seen within the sex vesicle. 


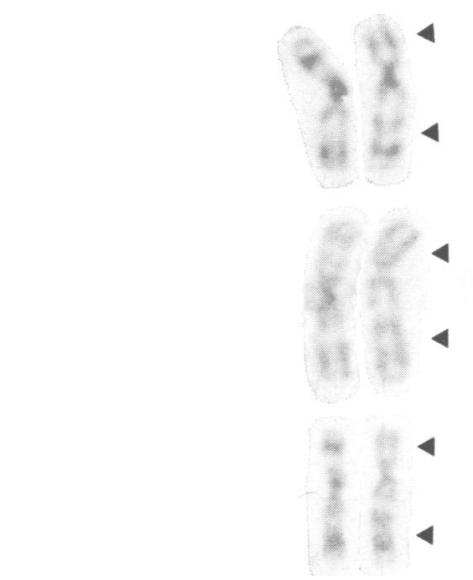

FIG 8 No 3 chromosomes from man with inversion of chromosome 3. Stained with trypsin Giemsa. The inverted chromosome is on the right.

Chromosome anomaly had not been suspected in one patient before biopsy but all 34 diakineses examined contained a large ring quadrivalent (fig 7 a, b). Careful re-examination of banded mitotic preparations revealed a reciprocal exchange between $2 \mathrm{q}$ and $10 \mathrm{q}$ (breakpoints at $\mathrm{q} 33$ and $\mathrm{q} 24$, respectively).

\section{Inversions}

A total of 60 cells at diakinesis were analysed from the patient with an inversion of chromosome 3 (fig 8 ). In 58 of these there was no detectable abnormality of pairing (fig 9a), but in two cells the position of the centromeres appeared to be asymmetrical (fig $9 \mathrm{~b}$ ). No abnormalities were detected at pachytene or at MII.

No abnormal configurations were seen in cells either at pachytene or at diakinesis in preparations from biopsies of the two men with an inversion of chromosome 9.

\section{TESTICULAR HISTOLOGY}

The results of the histological analysis are shown in table 3. Since there was no evident difference between biopsies from left and right testes, these observations were combined. The mean biopsy score was below the normal range for all patients except the 13;14 translocation carrier, whose tubular score distribution or 'profile' (fig 10) was indistinguishable from that of a normal fertile male.

It is apparent from fig 10 that the other four patients with major chromosome rearrangements have biopsy profiles which are characterised by a

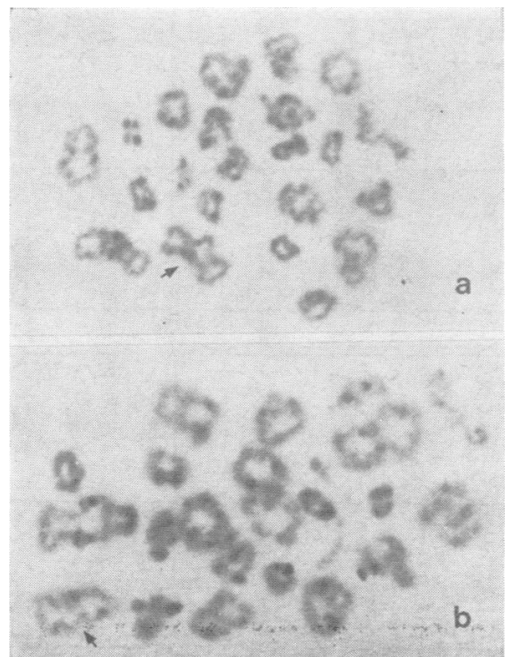

FIG 9 Cells in diakinesis from man with inversion of chromosome 3: the arrows indicate the presumed chromosome 3 bivalent. In (a), as seen in 58 cells, no abnormality is apparent. In (b), as seen in 2 cells, the centromeres appear to be asymmetrically placed.

failure of spermatogenesis which starts at the spermatocyte stage with no evidence of earlier suppression. In the case of the $X ; 21$ translocation there was complete suppression at this stage but in the others there was a less sharp effect with some tubules proceeding to more advanced stages. In particular, in the $\mathrm{Y} ; 16$ translocation, $10 \%$ of tubules contained scanty spermatozoa and the main block was at the second, rather than the first, meiotic division.

In contrast, the patient with the 47,XYY karyotype and the two patients with inversions of chromosome 9 had a general suppression of spermatogenesis with tubules showing a block at all stages.

Tangent counts $/ \mathrm{mm}^{2}$ were within the limits

TABLE 3 Histological analysis of testicular biopsies from 8 men with abnormal somatic karyotype

\begin{tabular}{|c|c|c|c|}
\hline Karyotype & $\begin{array}{l}\text { Mean } \\
\text { biopsy score }\end{array}$ & $\begin{array}{l}\% \text { volume } \\
\text { tubular } \\
\text { epithelium }\end{array}$ & $\begin{array}{l}\text { Tangent } \\
\text { counts } / \mathrm{mm}^{2}\end{array}$ \\
\hline $46, Y, t(X ; 21)$ & \multicolumn{3}{|c|}{ Insuffient material for analysis } \\
\hline $46, X, t(Y ; 16)$ & $6 \cdot 3$ & 57 & 24 \\
\hline $47, X Y Y$ & $4 \cdot 0$ & 34 & 16 \\
\hline $46, X Y, t(13 ; 14)$ & $9 \cdot 6$ & 57 & 20 \\
\hline $46, X Y, t(2 ; 10)$ & $6 \cdot 0$ & 52 & 24 \\
\hline $46, X Y$,inv 3 & $6 \cdot 3$ & 55 & 26 \\
\hline $46, X Y$, inv 9 & $5 \cdot 4$ & 43 & 26 \\
\hline $46, X Y$,inv 9 & $5 \cdot 2$ & 55 & 20 \\
\hline Normal range (Lamont et $a l^{5}$ ) & $8 \cdot 3-9 \cdot 9$ & $43-67$ & $12-27$ \\
\hline
\end{tabular}



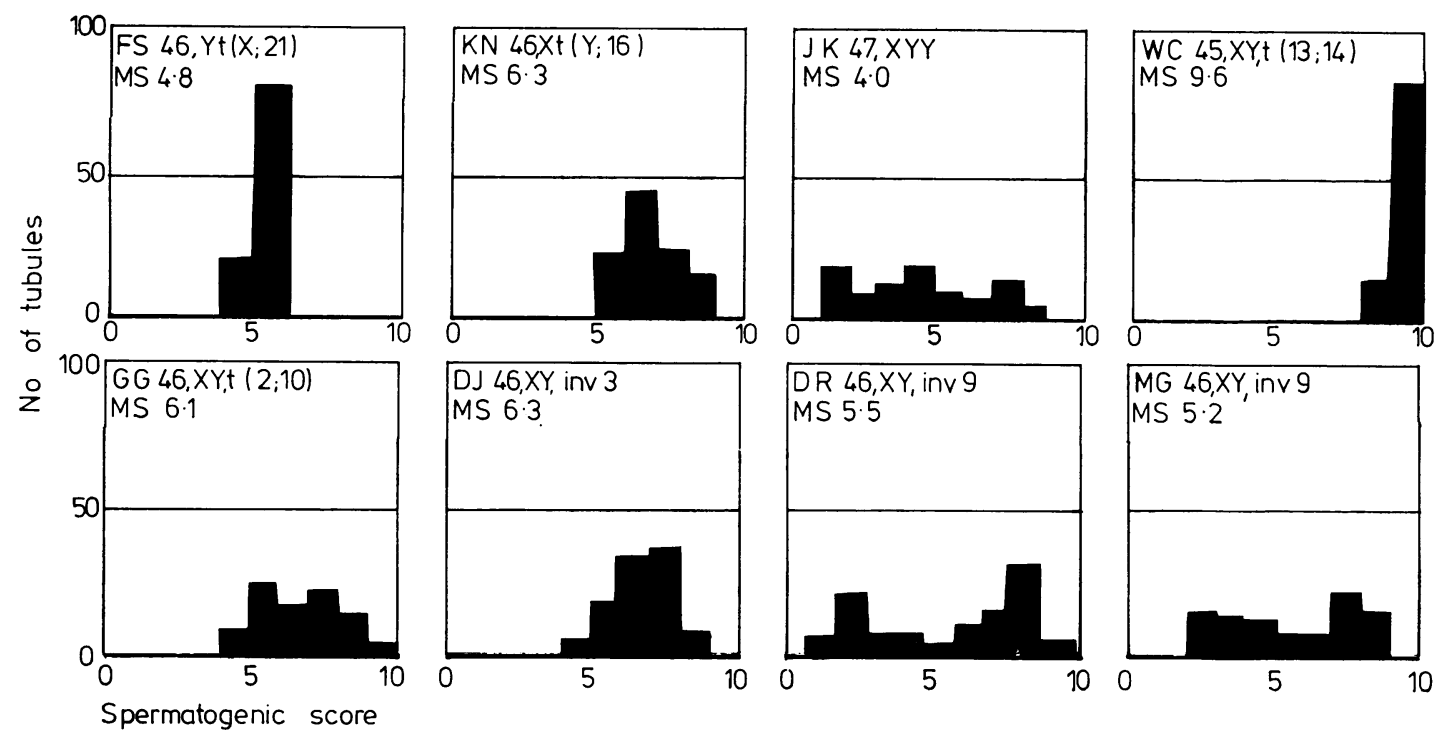

FIG 10 Tubular score 'profiles' from 8 men with abnormal karyotypes.

established for biopsies from normal fertile men. ${ }^{5}$ The percentage volume of testicular tissue occupied by tubular epithelium for all biopsies assessed, apart from that from the XYY patient, was also within the normal range. Only $34 \%$ of the total testicular tissue in the XYY patient consisted of tubular epithelium. Twenty percent of the tubules in this patient were atrophic.

\section{Discussion}

In this study we have attempted to quantify the testicular histology and stages of spermatogenesis of eight men with an abnormal chromosome complement and have examined these findings in the light of the behaviour of the abnormal chromosomes during meiosis.

One patient, with a 13;14 Robertsonian translocation and a history of only 2 years of involuntary infertility showed a biopsy profile indistinguishable from those we found in our series of normal fertile males. ${ }^{5}$ This patient had a sperm density of $20 \times 10^{6}$ sperms $/ \mathrm{ml}$ and his wife has subsequently given birth to a daughter with a normal $46, \mathrm{XX}$ chromosome complement. In all cells examined at diakinesis there was satisfactory pairing of the 13 and 14 with the translocation chromosome with chiasma counts within the normal range. Nevertheless, Robertsonian translocations between chromosomes 13 and 14 have been found in most surveys of subfertile males and appear to be four or five times more frequent than in the newborn population. ${ }^{3}$ Slightly reduced chiasma counts have been reported in both fertile and subfertile $13 \mathrm{q} ; 14 \mathrm{q}$ translocations carriers. ${ }^{4}$

The other patients fall into one of two groups determined by the stage at which spermatogenesis becomes affected. This is evident from the biopsy profiles. Four patients have tubules which develop normally until the primary spermatocyte stage but developmental blocks occur thereafter. These patients all have major rearrangements of chromosomal material. Three other patients had a biopsy profile which reflects spermatogenic failure affecting all stages, a pattern which is similar to that found in many subfertıle men with normal $46, X Y$ karyotype. $^{5}$ Two of these three patients had inversions of chromosome 9 , widely regarded as being a normal variant and probably without effect on meiosis ${ }^{\mathbf{1 2}}$ and the other was the patient with a 47,XYY karyotype. Although XYY men are not uniformly sutfertile, Skakkebaek et al ${ }^{13}$ have shown that out of eight XYY men not selected for subfertility, testicular histology was impaired in five. Most studies on meiosis in 47,XYY males have shown that some process leads to the loss of the second $\mathrm{Y}$ chromosome even for spermatogonial cells and it is not surprising that this apparent requirement results in the failure of a proportion of cells throughout spermatogenesis. ${ }^{\mathbf{1 4}}$

Of particular interest because very few other cases have been studied at meiosis are the sex chromosome/ autosome translocations.

The patient with an $X ; 21$ translocation showed a complete block at the spermatocyte stage with only 
a few degenerate pachytene figures. The few other reports of meiotic studies on human $\mathrm{X}$;autosome translocation carriers have shown inactive testicular tissue $^{15}$ or a block in spermatogenesis which allowed only a few cells of degenerate appearance to reach metaphase $\mathrm{I}^{16} \mathrm{~A}$ block at this stage is not characteristic of human autosomal translocations which suggests that the $\mathrm{X}$ chromosome may have some specific effect on spermatogenesis. The possible role of $\mathrm{X}$ chromosome inactivation in the vesicle has been discussed by Lifschytz and Lindsley. ${ }^{17}$ In the light of the possible importance of the sex vesicle it is interesting that the $Y ; 16$ translocation does not result in a complete block at this stage despite the clear evidence that the fluorescent part of the $Y$ chromosome, which is translocated to chromosome 16 , is included in the sex vesicle. Pajares et $a l^{18}$ reported a case of apparently balanced reciprocal translocation between chromosomes $\mathrm{Y}$ and 10. They found a halt at MI with just two cells, of poor quality, at diakinesis. In two different cases of $\mathrm{Y}$;autosome translocation in which $\mathrm{Yq}$ was translocated to chromosome $5^{19}$ or to chromosome $14,{ }^{20}$ the fluorescent part of the $Y$ was, as in our case, found in the sex vesicle and the effect on spermatogenesis was similar to ours. Thus the effect of a close association of autosomal material with the sex vesicle differs when the material is translocated to an $X$ and to $\mathrm{Y} Y$. $X$ and $Y$ autosome translocations have also been studied in male mice ${ }^{21}$ and the effects on spermatogenesis are essentially similar to those reported here for men.

All diakineses from the patient with a $2 ; 10$ translocation contained a ring quadrivalent. This patient was not azoospermic and his wife has since delivered a phenotypically normal male child. The azoospermic males reported by Chandley et al ${ }^{4}$ and San Roman et al $^{22}$ had chain quadrivalents in contrast to the ring quadrivalents found in males with apparently unimpaired spermatogenesis. ${ }^{423}$ This agrees well with the findings in mice in which the proportion of chains was found to be positively correlated with the extent of the depression of sperm production. ${ }^{24}$ Determination of the meiotic pairing behaviour in translocation heterozygotes may therefore have value in counselling subfertile males.

The patient with the inversion of chromosome 3 showed a late block in spermatogenesis with an abundance of spermatids but few spermatozoa. The possible relevance of the inversion to a block at this stage is not clear. There are at least five other apparently unrelated families known with inversions of chromosome 3 with breakpoints at the same or very similar positions and all were ascertained through an unbalanced child ${ }^{25-28}$ (Sutherland, 1979, personal communication) and showed no evidence of primary infertility in carriers : both the American ${ }^{27}$ and the Australian (Sutherland, 1979, personal communication) pedigrees are very extensive. In our case the centromeres of most of the bivalents seen at diakinesis, as shown on $\mathrm{C}$ banded preparations, were symmetrically placed and in only a few cells did the centromeres appear asymmetrical. Asymmetrically placed centromeres may be interpreted as being the result of homologous pairing between the distal uninverted portions of the chromosome. ${ }^{12}$ Whereas uneven numbers of chiasmata occurring between the limits of the inversion may be expected to lead to unbalanced recombinant chromosomes, exchanges occurring between distal uninverted segments would not. The relatively few cells seen with asymmetrical centromeres may therefore indicate a high risk of abnormal recombinants in this patient.

We have argued before ${ }^{29}$ that large inversions which are likely to give rise to small duplication/ deficiencies are more likely to result in viable but abnormal zygotes, and Winsor et al ${ }^{12}$ have shown that this holds for most published cases. This, however, leaves open the question as to whether large duplications and deficiencies bring about the early and undetected loss of zygotes or whether gametes with grossly unbalanced genetic material fail to be produced. In the cases reported here there are defects in spermatogenesis and it is striking that in the two autosomal translocation carriers, in whom the configurations at diakinesis give the greatest prospect of balanced gametes, spermatogenesis is least affected and the wives of both have subsequently given birth to normal children.

The comparison of biopsy score profiles with chromosomal status gives a valuable insight into the effect of the chromosomal abnormality on spermatogenesis. This study would further suggest, by comparison with the biopsy score profiles of subfertile men with a known 46,XY karyotype, that patients with certain categories of chromosomal anomaly may have characteristic biopsy profiles.

We thank Dr J Robertson for helpful discussions, Doris McLean for cytogenetic preparations from testicular biopsies, the staff of the Histopathology Laboratory for preparation of histological material, and Dorothy Morrison for typing the manuscript.

\section{References}

1 Koulischer L, Schoysman R. Étude des chromosomes mitotiques et méiotiques chez les hommes infertiles. $J$ Genet Hum (Suppl) 1975;23:58-70.

2 Chandley AC, Edmond P, Christie S, Gowans L, Fletcher J, Frackiewicz A, Newton M. Cytogenetics and infertility in man. 1. Karyotype and seminal analysis. Ann Hum Genet $1975 ; 39: 231-54$. 
${ }^{3}$ Faed MJW, Robertson J, Lamont MA, et al. A cytogenetic survey of men being investigated for subfertility. J Reprod Fertil 1979;56:209-16.

4 Chandley AC, Christie S, Fletcher J, Frackiewicz A, Jacobs PA. Translocation heterozygosity and associated subfertility in man. Cytogenetics $1972 ; 11: 516-33$.

${ }^{5}$ Lamont MA, Faed MJW, Baxby K. Comparative studies of spermatogenesis in fertile and subfertile men. $J$ Clin Pathol 1981;34:145-50.

6 Evans EP, Breckon G, Ford CE. An air-drying method for meiotic preparations from mammalian testes. Cytogenetics 1964;3:289-94.

7 Luciani JM, Morazzani MR, Stahl A. Identification of pachytene bivalents in human male meiosis using Gbanding technique. Chromosoma 1975;52:275-82.

8 Johnsen SC. Testicular biopsy score counts. A method for registration of spermatogenesis in human testes. Normal values and results in 335 hypogonadal males. Hormones $1970 ; 1: 2-25$.

${ }^{9}$ Dunnill MS. Quantitative methods in histology. In: Dyke $\mathrm{SC}$, ed. Recent advances in clinical pathology. Series V. London: Churchill, 1968: 401-6.

10 Averback P, Wight D. Seminiferous tubule hypercurvature: a newly recognised common syndrome of human male infertility. Lancet $1979 ; \mathbf{i}: 181-3$.

11 Faed MJW, Robertson J, MacIntosh WG, Grieve J. Spermatogenesis in an infertile XYY man. Hum Genet 1976;33:341-7.

12 Winsor EJT, Palmer CG, Ellis PM, Hunter JLP, Ferguson-Smith MA. Meiotic analysis of a pericentric inversion, inv (7) (p22q32) in the father of a child with a duplication-deletion of chromosome 7. Cytogenet Cell Genet 1978;20:169-84.

13 Skakkebaek NE, Hultén M, Jacobsen P, Mikkelsen M. Quantitation of human seminiferous epithelium II. Histological studies in eight 47,XYY men. $J$ Reprod Fertil $1973 ; 32: 391-401$.

14 Melynk J, Thompson H, Rucci A, Vanasek F, Hayes S. Failure of transmission of the extra chromosome in subjects with 47,XYY karyotype. Lancet 1969 ;ii:797.

15 Buckton KE, Jacobs PA, Rae LA, Newton MS, Sanger R. An inherited X-autosome translocation in man. Ann Hum Genet $1971 ; 35: 171-8$.

16 Dutrillaux B, Couturier J, Rotman J, Salat J, Lejeune J. Stérilité et translocation familiale $\mathrm{t}(1 \mathrm{q}-; \mathrm{Xq}+) . C R$ Acad Sci Paris (D) 1972;274:3324-7.
17 Lifschytz E, Lindsley DL. The role of X-chromosome inactivation during spermatogenesis. Proc Natl Acad Sci USA 1972;69:182-6.

18 Pajares IL, Delicado A, Colbos PV, Corral FS, Cuadrado C. An azoospermic male with a Y/autosome translocation. Hum Genet 1979;46:155-8.

19 Dutrillaux B, Gueguen J. Étude meiotique et mitotique dans un cas de translocation $\mathrm{t}(5 ; \mathrm{Y})$. Humangenetik $1975 ; 27: 241-5$.

20 Laurent C, Dutrillaux B. Translocation $\mathrm{t}(\mathrm{Y} ; 14)$ chez un homme azoospermique. Ann Genet (Paris) 1976;19:207-9.

${ }^{21}$ Searle AG, Beechey CV, Evans EP. Meiotic effects in chromosomally derived male sterility of mice. Ann Biol Anim Biochim Biophys 1978;18 (2B):391-8.

${ }^{22}$ San Roman C, Sordo MT, Garcia-Sagredo JM. Meiosis in two human reciprocal translocations. J Med Genet $1979 ; 16: 56-9$.

23 Ferguson-Smith MA, Page B (1973). Quoted in Winsor et al. Cytogenet Cell Genet $1978 ; 20: 169-84$

24 Searle AG. Nature and consequences of induced chromosome damage in mammals. Genetics 1974;78: 173-86.

25 Boué J, Hirschhorn K, Lucas M, Goutier M, Moszer M, Bach C. Aneusomies de recombinaison. Consequences d'une inversion pericentrique d'un chromosome 3 paternel. Ann Pediatr 1974;21:567-73.

26 Lurie IW, Lazyuk GI, Gurevich DB. Medico-genetical consulting of persons with pericentric inversions. Genetika 1974; $10: 136-41$

27 Allderdice PW, Browne N, Murphy DP. Chromosome 3 duplication $\mathrm{q} 21 \rightarrow$ qter deletion p25 $\rightarrow$ pter syndrome in children of carriers of a pericentric inversion inv (3) (p25 q21). Am J Hum Genet 1975;27:699-718.

28 Kawashima H, Maruyama S. A case of chromosome 3 duplication $\mathrm{q}$ deletion $\mathrm{p}$ syndrome born to the mother with a pericentric inversion, inv (3) (p25 q21) Jpn J Hum Genet 1979;24:9-12.

29 Faed MJW, Marrian VJ, Robertson J, Robson EB, Cook, PJL. Inherited pericentric inversion of chromosome 5 . A family with history of neonatal death and a case of the 'cri du chat' syndrome. Cytogenetics 1972;11:400-11.

Requests for reprints to $\mathrm{Dr} M \mathrm{~J}$ W Faed, Cytogenetics Laboratory, Ninewells Hospital and Medical School, Dundee DD1 9SY. 